\title{
REVISITAR O CONCEITO DE COMUNIDADE PARA DISCUTIR SUA APLICAÇÃO A CONTEXTOS TELECOLABORATIVOS
}

\author{
Laura RAMPAZZO* \\ Solange ARANHA **
}

- RESUMO: O objetivo deste artigo é discutir o conceito de comunidade em contextos multimodais de projetos telecolaborativos, especificamente o teletandem (TELLES, 2006). Comunidades discursivas (CD) são agrupamentos de indivíduos que se unem para atingir seus propósitos comunicativos por meio de gêneros (SWALES, 1990). Embora o conceito tenha sido extensivamente discutido em contextos acadêmicos, parece não haver estudos que envolvam o tema e sua importância para a telecolaboração. Uma tentativa nesse sentido é o trabalho de Silva (2012) sobre a comunidade teletandem (CT), no qual a autora investiga os estudantes que participam do projeto Teletandem Brasil: Linguas Estrangeiras para Todos. Partimos dos critérios elaborados por Silva para a definição de CT e nossa análise deriva de nossa observação intensa e criteriosa da prática de teletandem no laboratório de teletandem da UNESP - São José do Rio Preto. Os resultados indicam que os membros de comunidades que eventualmente se agrupam em contextos telecolaborativos tendem a serem regulados por regras locais e externas, engendrarem organizações complexas e compartilharem gêneros para alcançarem seus objetivos.

- PALAVRAS-CHAVE: Telecolaboração. Comunidade Discursiva. Comunidade Teletandem. Gêneros.

\section{Introdução}

O avanço das tecnologias digitais de informação e comunicação facilitou o contato entre pessoas de diferentes línguas e culturas que provavelmente não teriam a chance de se comunicarem umas com as outras devido à distância geográfica. O desenvolvimento tecnológico também permitiu o uso de ferramentas de comunicação síncrona com propósitos pedagógicos, o que culminou na criação de projetos telecolaborativos, definidos por O’Dowd (2013) como projetos que promovem interação intercultural entre estudantes de línguas que estão localizados em lugares distintos.

\footnotetext{
Instituto Federal de Educação, Ciência e Tecnologia de São Paulo (IFSP), Barretos - SP - Brasil. laura.rampazzo@, ifsp.edu.br. ORCID: 0000-0002-4736-9900

** Universidade Estadual Paulista (UNESP), São José do Rio Preto - SP - Brasil. Departamento de Letras Modernas. solange.aranha@unesp.br. ORCID: 0000-0002-8092-1875
} 
Dentre as iniciativas telecolaborativas para a aprendizagem de línguas ao redor do mundo, há, no Brasil, o projeto Teletandem Brasil: Línguas Estrangeiras para Todos (TELLES, 2006). Desenvolvido desde 2006 na Universidade Estadual Paulista (UNESP), o projeto promove o contato entre estudantes universitários brasileiros aprendizes de uma língua estrangeira e estudantes universitários do exterior que estão estudando português. Os aprendizes se encontram semanalmente por meio de ferramentas de comunicação síncrona a fim de ajudarem o outro na aprendizagem de sua língua nativa (ou língua de proficiência).

O desenvolvimento desse projeto levou à formação de grupos de pessoas envolvidas na prática de teletandem no campus da Unesp de São José do Rio Preto, onde a modalidade de teletandem institucional integrado ocorre. Essa modalidade inclui os aprendizes, que desejam melhorar suas habilidades na língua estrangeira; seus professores, que podem se interessar por incorporar a prática de teletandem às suas aulas de línguas; e pesquisadores, que podem encontrar no teletandem um campo rico para pesquisas, que pode ser investigado sob múltiplas perspectivas teóricas (ARANHA; CAVALARI, 2014).

Considerando que são vários os indivíduos envolvidos na prática de teletandem e que eles parecem trabalhar em direção a objetivos comuns (prática de línguas, melhoria de oportunidades pedagógicas, trocas culturais e pesquisa), eles provavelmente formam uma comunidade discursiva nos termos de Swales (2016), uma vez que usam gêneros para alcançar seus propósitos comunicativos. Silva (2012) propôs uma investigação a respeito dos participantes de teletandem, no intuito de verificar se eles formariam uma comunidade ou não. Entretanto, a autora apenas considera a participação dos estudantes/aprendizes, não levando em conta o papel desempenhado por professores e pesquisadores nesse contexto. A esse respeito, Rampazzo (2017) já havia argumentado por uma revisão dos resultados de Silva (2012) a fim de que o conceito fosse ainda válido para descrever o que acontece atualmente entre os envolvidos nas atividades de teletandem.

O propósito deste trabalho é discutir o conceito de comunidade discursiva em contextos multimodais, multiculturais e telecolaborativos, especificamente, o contexto de teletandem. Defendemos que a relevância deste estudo reside no fato de que a noção de pertencer ou não a uma comunidade (LEVY, 1999) pode determinar o (in)sucesso de um indivíduo no que diz respeito ao atingimento de seus objetivos (ARANHA; TELLES, 2011) e também resultar na aculturação do comportamento de membros mais antigos. Além disso, parece haver uma lacuna de estudos que relacionam os conceitos de comunidades e telecolaboração.

Primeiramente, apresentamos uma revisão teórica do conceito de comunidade discursiva a partir de Swales (1990, 1998, 2016) e os critérios da comunidade teletandem desenvolvidos por Silva (2012), os quais incorporam as discussões de Swales (1990), Wenger (1998) e Levy (1999). Então, introduzimos os métodos usados neste estudo e damos mais detalhes sobre o contexto investigado. Em seguida, trazemos a análise e, por fim, a discussão. 


\section{Fundamentação teórica}

O conceito de comunidade discursiva (CD) aparece, primeiramente, em Swales (1990). Inicialmente, essa definição aparece associada a dois outros conceitos: o de gênero e o de tarefa (para aprendizagem de línguas). Se, por um lado, poucos estudos com base na abordagem sociorretórica de gêneros se concentraram no conceito de tarefa, a comunidade discursiva não pôde ser definida sem uma estreita relação com o conceito de gênero, uma vez que é a comunidade que desenvolve e utiliza os gêneros para servirem a seus propósitos (SWALES, 1990).

Swales (1990) apresenta os gêneros como eventos comunicativos utilizados por um grupo de indivíduos - a comunidade discursiva -, que se une a fim de alcançar seus propósitos comunicativos públicos e compartilhados. Sua definição estabelece que os gêneros resultam das necessidades da comunidade, isto é, que os membros criam estruturas discursivas padronizadas como uma resposta às demandas de realização de tarefas e à necessidade de cumprir seus propósitos comunicativos.

Em relação à definição de gênero, Miller (1984) enfatiza que os gêneros moldam a ação social, ajudando a construir a substância da nossa vida cultural, uma característica também destacada por Swales (1990), que argumenta que os gêneros oferecem possibilidades e restrições em sua estrutura, conteúdo e estilo. Em 2004, Swales acrescenta que os gêneros moldam a forma como as pessoas interagem e oferecem regras que refletem aquilo que é social e retoricamente apropriado em certas situações sociais.

Com base no que foi exposto, podemos dizer que os gêneros cumprem as demandas de uma comunidade discursiva ao mesmo tempo em que organizam suas ações. A respeito dessa relação indissociável, Aranha (1996, p.21) afirma que

[...] o gênero se estabelece dentro de uma comunidade discursiva e ela se torna responsável por ele. Poderíamos sugerir que existe um processo de autoalimentação: a comunidade discursiva desenvolve determinados gêneros e a existência de gêneros específicos configura grupos sociais como comunidades discursivas por compartilharem propósitos comunicativos efetivados através dos gêneros pertinentes a ela.

Assim, podemos argumentar que os gêneros não existem se não há uma comunidade para fazer uso deles e vice-versa: se não se encontram gêneros em uma comunidade, ela não pode ser validada como tal.

Quanto à caracterização da comunidade discursiva (CD), Swales (1990) apresenta alguns critérios que validariam um grupo como CD. No entanto, como Hemais e Biasi-Rodrigues (2005) destacam, a definição de Swales (1990) não é suficiente para analisar o processo de formação de um grupo, uma vez que é válida tão somente para comunidades já estabelecidas e consolidadas. O próprio Swales (1993) admite que o conceito, como proposto inicialmente, não poderia ser encontrado no mundo real. Em 1998, ele concorda com as críticas que sugeriam que o conceito era utópico e idealista. 
Além disso, em 2016, o autor declara que a primeira definição de CD era muito estática e não dava conta de explicar como as pessoas entravam ou saíam das comunidades. Em suas palavras:

[...] conceito de comunidade discursiva tal como concebido originalmente era excessivamente estático. Embora talvez isso não importasse muito em 1990, no mundo de hoje, mais instável e incerto, isso emerge como um problema; especificamente, o conceito não abordava como as pessoas ingressavam ou saíam das CDs (SWALES, 2016, p. 11, tradução nossa) ${ }^{1}$.

Devido aos inúmeros comentários contrários à descrição estática do conceito, Swales (1998) propõe novos critérios para verificar se um grupo de indivíduos poderia ser descrito como uma CD. Os critérios deveriam ser exaustivos o suficiente para distinguir os grupos que detêm o status de comunidade daqueles que não o têm. $\mathrm{O}$ autor apresenta uma textografia dos três andares de um prédio na Universidade de Michigan para chegar aos conceitos de comunidade discursiva de lugar e comunidade discursiva focal. Naquele momento, ele se concentra no primeiro conceito, mas volta a discutir a comunidade discursiva focal em um artigo publicado recentemente (SWALES, 2016).

A comunidade discursiva de lugar é definida como um conceito nem tão vago nem tão restritivo. Em outras palavras, é uma definição que pretende não ser instável e confusa para que pudesse ser usada para descrever qualquer agrupamento de pessoas, nem tão perfeccionista a ponto de restringir os grupos que pudessem ser classificados como uma CD. Swales propõe que o conceito descreva um grupo de pessoas que trabalham juntas regularmente e explica que seus membros estão cientes de seus papéis e objetivos e desenvolvem gêneros orais e escritos a fim de atingirem seus propósitos comunicativos. $\mathrm{O}$ autor também declara que os gêneros possuem características retóricas e discursivas, que podem ser reconhecidas por membros mais antigos e funcionar como um sistema para validar as ações de uma comunidade também fora dela. Outro aspecto da comunidade discursiva de lugar é a criação de um léxico específico e um sistema de valor daquilo que pode ser considerado um bom (ou mau) trabalho. Além disso, uma comunidade discursiva de lugar tem ciência de sua história e tenta compartilhar suas tradições a novos membros para que estes saibam como participar apropriadamente de suas práticas discursivas.

Após quase 20 anos de sua última discussão sobre o tema (SWALES, 1998), em 2016, Swales explora três tipos de comunidades discursivas e então reflete a respeito dos critérios originais de 1990, atualizando-os e acrescentando outros dois. O primeiro tipo é a comunidade discursiva local, que apresenta várias semelhanças ao conceito de comunidade discursiva de lugar de 1998. Swales (2016) declara que os membros desse tipo de comunidade trabalham no mesmo local ou têm a mesma ocupação na

No original: "[...] the concept of discourse community as originally conceived was overly static. While this perhaps did not matter so much in 1990, in today's more unsettled and uncertain world, it looms larger as a problem; in particular, the concept did not firmly or directly address how people either join or leave DCs". (SWALES, 2016, p. 11). 
mesma área; desenvolveram uma terminologia que não é utilizada ou compreendida pelo público geral; e passam por um período de triagem, quando tentam assimilar os comportamentos de membros mais antigos.

O segundo tipo é a comunidade discursiva focal, mencionada anteriormente em 1998. Essa comunidade é tratada como uma associação que não se restringe a uma região, visto que seus membros podem ser de diferentes nacionalidades, idades, ocupações, circunstâncias econômicas e formações acadêmicas. De acordo com o autor, a comunidade discursiva focal pode ser informal ou formal, mas desenvolve um conjunto de regras. Comunidades discursivas focais podem se formam tanto por suas preferências recreacionais quanto por razões profissionais.

O terceiro tipo, a comunidade discursiva "folocal", representa uma comunidade híbrida, que têm as características dos dois tipos anteriores. Swales (2016) propõe que os membros da CD folocal têm dois comprometimentos, sendo confrontados por pressões internas e externas. Em outras palavras, esses membros têm comprometimentos duplos porque se dedicam tanto a fatores locais quanto externos; eles precisam observar as demandas locais e focais.

Em vista da existência de diferentes tipos de comunidades discursivas e dos problemas que a definição original apresentou, em 2016, Swales apresenta uma reconsideração dos critérios para definição e reconhecimento de comunidades discursivas. Ele argumenta que: (1) um CD tem um conjunto de objetivos, os quais podem ser descobertos, formulados publicamente e reconhecidos por seus membros; (2) uma CD tem mecanismos de intercomunicação e atualmente podem contar com novas tecnologias digitais; (3) uma $\mathrm{CD}$ usa de seus mecanismos participatórios não apenas para oferecer feedback, mas também para gerenciar operações, promover recrutamento, mudanças e crescimento; (4) uma CD usa uma seleção de gêneros que se desenvolvem a medida em que são usados e reutilizados; (5) uma CD desenvolve uma terminologia específica que auxilia na promoção de eficiência; (6) existe uma hierarquia implícita ou explícita em uma CD que controla os processos de entrada e progressão e, por isso, alguns membros têm mais experiência discursiva; (7) uma CD desenvolve um senso de "relações silenciais", o que significa dizer que há aspectos na comunidade que não precisam ser ditos ou explicados em detalhe; (8) uma CD tem uma percepção de sua história e um sistema de valor daquilo que pode ser considerado um bom ou mau trabalho.

A discussão de comunidade discursiva proposta por Swales ao longo dos anos teve como foco o nível acadêmico e os gêneros de pesquisa que são usados nesse contexto. No que diz respeito aos contextos telecolaborativos, ainda são poucos os trabalhos que refletem a respeito do conceito ou o utilizam para explicar as relações entre seus membros. Darhower (2007) conduz um estudo sobre um projeto telecolaborativo chamado Bilingula Chat Community, em que falantes de inglês e espanhol interagem por meio do chat. Ele argumenta que a telecolaboração é, por natureza, comunidades de aprendizagem virtuais e tenta identificar os comportamentos linguísticos e sociais que definem o processo de formação de uma comunidade e de se tornar um participante/ 
membro pleno. A partir da definição de comunidade de prática (LAVE; WENGER, 1991), o autor defende que os aprendizes idealmente desenvolveriam a habilidade de se comunicar na língua da comunidade e agir conforme suas regras.

A esse respeito, poderíamos argumentar que aprender como uma comunidade trabalha e como seus membros realizam suas ações é essencial para que os novatos sejam bem-sucedidos em sua tentativa de se tornarem membros plenos de uma comunidade. Em relação ao sucesso, Aranha e Telles (2011), um dos primeiros estudos a relacionar gêneros e teletandem, acreditam que o compartilhamento de propósitos comunicativos é vitalmente importante para que as parcerias não integradas sejam bem-sucedidas, ou seja, durem mais tempo. Os autores destacam que a variedade de textos produzidos no ambiente de teletandem pode corresponder a gêneros e que, se estes não são compartilhados pelos participantes, uma interrupção na parceria pode acontecer. Em razão disso, poderíamos sugerir que os argumentos desses autores já indicam uma possível formação de uma comunidade no contexto de teletandem, uma vez que um dos critérios proposto por Swales $(1990,1998,2016)$ para validar uma comunidade é o fato que os participantes compartilham dos mesmos propósitos ou têm propósitos similares.

Silva (2012) investiga se o agrupamento de estudantes que participavam do projeto Teletandem Brasil tinha as características de uma comunidade - a comunidade de teletandem, com base nos conceitos de comunidade discursiva (SWALES, 1990), comunidade de prática (CP) (WENGER, 1998) e comunidade virtual (CV) (LEVY, 1999). De acordo com a autora, nenhuma definição por si só parecia ser suficiente para descrever a associação de estudantes no teletandem. A autora explica que nas três definições, os membros das comunidades: (i) compartilham propósitos em comum; (ii) têm mecanismos de intercomunicação; (iii) não se restringem a barreiras geográficas; (iv) compartilham relações de troca, reciprocidade e sentem que pertencem ao grupo; e (v) compartilham um conjunto de regras. Os três conceitos se distinguem no sentido de que a CD se situa no nível do discurso e seus membros compartilham gêneros para alcançar seus propósitos, enquanto que a CP se situa no nível da prática e os membros trabalham juntos a fim de melhorarem sua prática. Além disso, os membros de uma $\mathrm{CP}$ costumam estar em contato direto uns com os outros e os membros da CV estão sempre em contato virtual. Tanto na $\mathrm{CP}$ quanto na $\mathrm{CD}$, os membros podem navegar em contatos físicos e virtuais.

A partir das semelhanças e diferenças entre os três conceitos de comunidade, Silva (2012) estabelece seis critérios para identificação da comunidade teletandem (CT):

1. Uma comunidade de teletandem se estabelece a partir de afinidades de interesses, objetivos em comum, compartilhamento de um mesmo conhecimento e de prática;

2. As interações entre seus membros são realizadas com frequência, tendo como base um processo de cooperação ou de troca (reciprocidade) (feedback) e a construção do conhecimento, provocando um sentimento de pertencimento; 
3. Os membros de uma comunidade de teletandem são "não-presentes", desterritorizados;

4. Uma comunidade de teletandem cultiva formas próprias de comunicação virtuais;

5. As comunidades de teletandem desenvolvem um conjunto de regras, coletivamente, que regem suas interações ("netiqueta");

6. Os membros de uma comunidade de teletandem compartilham um léxico específico e uma comunicação bilíngue. (SILVA, 2012, p. 72).

Após estabelecer os critérios, Silva (2012) selecionou 86 participantes de teletandem, brasileiros e estrangeiros, realizou entrevistas semiestruturadas e solicitou que eles respondessem a um questionário ${ }^{2}$. Seu objetivo era verificar se os critérios propostos eram válidos para descrever contextos de aprendizagem como o teletandem.

Em relação a seu primeiro critério, sobre o compartilhamento de objetivos, conhecimento e prática, Silva (2012) revela que a maioria dos participantes afirmou que seu objetivo principal no teletandem era aprender e melhorar sua habilidade na língua estrangeira. A segunda resposta mais comum foi a oportunidade de conhecer outra cultura. A autora acredita então que seu primeiro critério da CT é válido, uma vez que as respostas dos participantes demonstram que os membros possuem propósitos compartilhados.

O segundo item na sua definição da CT também se confirma. De acordo com as respostas dos participantes, eles trocam informações linguísticas e culturais e se sentem parte do contexto. Os estudantes também disseram que interagiam frequentemente e no horário previamente estabelecido com o parceiro, na modalidade não-integrada, ou pelos professores, se a prática era integrada à aula de língua.

Os critérios três e quatro da definição de CT também foram corroborados pelas respostas ao questionário. Eles estabeleciam que os membros da comunidade não tinham um território físico e entravam em contato de modo virtual.

O quinto critério estabelece que os membros criam um conjunto de regras que regulam as interações. Os participantes responderam que criavam regras e acreditavam que existiam demandas a ser cumpridas. Os estudantes salientaram que combinavam como iriam se corrigir, as datas para trocarem texto e obedeciam aos princípios de tandem (BRAMMERTS, 1996). A autora concluiu que esse critério também é válido.

Por fim, Silva (2012) argumenta que seu último critério também é legítimo, uma vez que os participantes confirmaram que a comunicação era bilíngue, por conta do princípio de separação de línguas, e que utilizavam emoticons, considerados pela autora como léxico especializado.

A autora realizou três entrevistas e, embora tenha enviado o questionário a todos participantes dos três campi, apenas 67 responderam. 
Em conclusão, pode-se afirmar que os membros da comunidade teletandem trabalham juntos para alcançarem objetivos comuns. A fim de fazê-lo, eles usam duas línguas e seguem as regras previamente estabelecidas.

\section{Metodologia}

A investigação apresentada aqui é um estudo qualitativo. Por conta de sua natureza aberta e flexível, esse paradigma permite que sejam feitos ajustes enquanto o estudo está em andamento. A esse respeito, Mason (2002) questiona se é possível planejar uma pesquisa qualitativa, dadas suas características fluidas e flexíveis. A autora aponta que os estudos qualitativos rejeitam um plano de pesquisa previamente fixo, dedutivo. Isso porque as decisões em relação ao planejamento são feitas ao longo da pesquisa, uma vez que os estudos qualitativos têm uma natureza exploratória, orientada pelos dados e sensíveis ao contexto. Além disso, Dörnyei (2007) destaca que as pesquisas qualitativas tentam capturar, em maiores detalhes, o contexto em que os dados são gerados e sustentam um contato intenso e duradouro entre pesquisador e dados.

Em relação à análise, os resultados são definidos pelo exame subjetivo das pesquisadoras, o que caracteriza este estudo como interpretativo. Segundo MoitaLopes (1994), nos estudos interpretativos, a análise é conduzida indiretamente, isto é, é desenvolvida com base na interpretação dos diversos sentidos que constituem um fato. $\mathrm{O}$ autor também explica que o acesso aos sentidos ocorre por meio do uso de instrumentos que apresentam descrições do contexto social.

Quanto a este estudo, nossa interpretação dos fatos se baseia em nossa observação da prática de teletandem na UNESP- campus de São José do Rio Preto de diversos grupos. Foram examinadas as relações entre os participantes que se engajam na prática de teletandem (estudantes, mediadores e professores), e os trabalhos a respeito de ambientes telecolaborativos para a aprendizagem de língua. Posteriormente, foram descritas as características desse contexto a partir da teoria de gêneros de abordagem sociorretórica. Em outras palavras, confirmamos quais aspectos do agrupamento que ocorre no teletandem podiam ser explicados pela teoria e se esse agrupamento podia ser definido em termos de uma comunidade discursiva.

\section{O contexto de teletandem na UNESP}

Como exposto acima, o teletandem é um projeto telecolaborativo que se desenvolve na UNESP, campi de São José do Rio Preto e Assis desde 2006 e Araraquara desde 2012. Os propósitos desse projeto são dois: pedagógico, com o objetivo de melhorar as competências linguística e cultural de estudantes universitários; e acadêmico ${ }^{3}$, com

A maioria dos estudos sobre teletandem podem ser encontrados no site: http://www.teletandembrasil.org/publications. html. Acesso em: 13 ago. 2019. 
o objetivo de oferecer um contexto profícuo e propício para se estudar a aprendizagem de línguas sob diferentes abordagens dentro da Linguística Aplicada.

No teletandem, falantes nativos (ou proficientes) de línguas distintas formam pares que se encontram semanalmente como o intuito de aprender a língua do outro em um ambiente telecolaborativo mediado por tecnologia VoIP, como o Skype. Na UNESP, campus de São José do Rio Preto, cada encontro (nomeado SOT - Sessão Oral de Teletandem) dura aproximadamente 50 minutos e os participantes devem dedicar metade do tempo para a prática de cada língua. Fazer parte do projeto também implica na participação dos estudantes em sessões de mediação, definidas por Funo (2015) como encontros face-a-face ou virtuais, em grupos ou individualmente - participante(s) e mediador - com o objetivo de encorajar a autonomia e promover reflexão. No campus de São José do Rio Preto, as sessões de mediação ocorrem em grupos após as sessões orais e por meio dos diários reflexivos comentados pelos professores.

Essa divisão da sessão em duas línguas está em conformidade com os princípios de teletandem. Baseados no tandem (BRAMMERTS, 1996), os princípios de teletandem são (i) separação de línguas, (ii) autonomia e (iii) reciprocidade (VASSALLO; TELLES, 2006). Enquanto o primeiro estabelece que os participantes devem ter a mesma quantidade de tempo para praticar a língua um do outro, o princípio da autonomia estabelece que os estudantes devem ser autônomos o bastante para tomarem suas próprias decisões quanto ao seu processo de aprendizagem. Segundo o princípio da reciprocidade, os participantes devem investir igualmente no processo de aprendizagem de seu par e se alternarem nos papéis de tutores de sua própria língua e aprendizes da língua do outro. Esses princípios unem as ações telecolaborativas sob termo teletandem.

A prática de teletandem pode se organizar em diferentes modalidades. A esse respeito, Aranha e Cavalari (2014) e Cavalari e Aranha (2016) descrevem as modalidades institucional integrada e institucional não-integrada e Zakir (2015) e Cavalari (2018) apresentam uma breve descrição do teletandem institucional semi-integrado. No teletandem institucional não-integrado, estudantes voluntários têm o apoio da instituição, mas são responsáveis pela logística da parceria: marcar os encontros, determinar a duração da parceria, monitorar o uso de ambas as línguas, avaliar sua performance e resolver quaisquer conflitos. Aranha e Cavalari (2014) nomeiam teletandem institucional integrado (TTDii) a modalidade em que (1) os participantes estão matriculados em disciplinas de línguas nas duas instituições; (2) a participação no TTDii é obrigatória; (3) parte das tarefas são propostas pelos professores de línguas; e (4) os estudantes são avaliados quanto às tarefas que realizam colaborativamente. Nessa modalidade, cada estudante brasileiro é pareado com um estudante de uma universidade no exterior e todos participantes inscritos realizam suas sessões orais de teletandem no mesmo horário, durante suas aulas de língua e em um ambiente apropriado. Os professores precisam concordar a respeito do calendário de interações que incluem a duração e as datas de quando as sessões orais vão ocorrer. Eles ainda precisam decidir quais as tarefas que serão desenvolvidas pelos estudantes. Além disso, no TTDii, como exposto em Aranha, 
Luvizari-Murad e Moreno (2015), em Luvizari-Murad (2016) e em Aranha e Lopes (2019), a coleta de dados é feita de modo sistêmico em grupos cujos participantes autorizaram compartilhar seus dados para fins de pesquisa.

A modalidade de teletandem institucional semi-integrada (TTDisi) acontece na UNESP campus de São José do Rio Preto quando os calendários de aulas nas duas instituições envolvidas em uma parceria não coincidem e, como resultado, não é possível integrar a prática às aulas de línguas na universidade brasileira. Nesse contexto, a prática de teletandem é obrigatória aos estudantes matriculados nas aulas de português na universidade no exterior e os participantes brasileiros são voluntários. Embora seja outra modalidade, o TTDisi é bastante semelhante ao TTDii, uma vez que as sessões orais também se realizam no mesmo horário e local com todos os participantes e há o desenvolvimento de tarefas. O grupo de voluntários conta com um mediador, normalmente um estudante de pós-graduação, que irá guiá-los ao longo da prática, explicar as tarefas e oferecer qualquer apoio que possam precisar.

Em relação às tarefas, Cavalari e Aranha (2016) são as primeiras autoras a descrever aquelas que ocorrem na prática de TTDii. As autoras as chamam de tarefas integradoras e apresentam algumas características destas. Sua descrição explica cada tarefa sem apontar uma hierarquia entre elas, destacando que a prática de teletandem alimenta as tarefas e são alimentadas por elas. A esse respeito, Aranha e Leone $(2016,2017)$ propõem que a prática de teletandem é composta por cenários pedagógicos, uma noção definida por Foucher (2010) para descrever quais tarefas são didaticamente planejadas para determinado ambiente de aprendizagem. Um cenário pedagógico envolve os objetivos, as competências prévias e as que pretendem ser alcançadas, os recursos e instrumentos, as tarefas e os possíveis interagentes. No teletandem, o conceito vem sendo utilizado para descrever as macro e micro-tarefas definidas para uma parceria (ARANHA; LEONE, 2016).

Os cenários pedagógicos no teletandem são caracterizados por duas macro-tarefas: as sessões orais de teletandem (SOT) e as sessões de mediação. Apesar de os cenários variarem dependendo do que os professores definem fazer, essas duas macro-tarefas são parte de qualquer parceria de teletandem. As autoras explicam que usam os termos tarefas, macro-tarefas e micro-tarefas para ilustrar a prática de teletandem como um ambiente complexo. Baseadas em Mangenot e Soubrié (2010), elas usam macro-tarefas para descrever aquelas de maior escopo e micro-tarefas para descrever as que contribuem para a implementação geral de tarefas. As autoras oferecem uma figura para ilustrar um cenário pedagógico possível: 
Figura 1 - A organização de um cenário pedagógico no Teletandem.

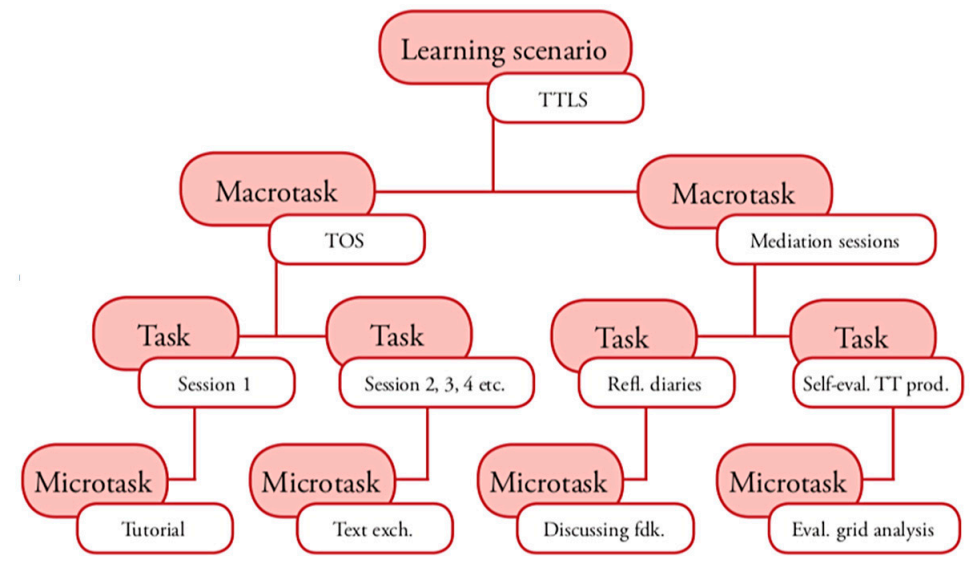

Fonte: Aranha e Leone (2017, p. 180).

Na figura, é possível observar que cada macro-tarefa dá origem a tarefas que têm micro-tarefas associadas a elas. A macro-tarefa SOT, então, compreende cada sessão oral que ocorre em uma parceira, isto é, os encontros virtuais e síncronos entre os parceiros. Relacionadas às sessões, Aranha e Leone (2017) incluem várias microtarefas, tais como o tutorial, uma reunião inicial em que o professor da disciplina e/ou pesquisadores do teletandem introduz o contexto telecolaborativo de aprendizagem de línguas, seus princípios e outras micro-tarefas relacionadas ao teletandem. Algumas informações sobre esses procedimentos podem ser encontradas em um site ${ }^{4}$ por meio de dicas em vídeo. Outra micro-tarefa ligada à SOT é a troca de texto que pode acontecer em uma parceria. De acordo com o cronograma de suas aulas, os estudantes devem escrever um texto na língua alvo sobre um tópico definido por seu professor e enviar aos parceiros, os quais devem revisá-lo, enviar de volta com sugestões para melhoria e discutir os resultados da escrita e revisão na sessão oral seguinte.

Na macro-tarefa de sessão de mediação, há outras micro-tarefas relacionadas. Uma delas é o diário de aprendizagem, que os estudantes precisam escrever após cada SOT a fim de refletir sobre sua experiência na prática de teletandem e pensar a respeito das estratégias que podem ser usadas para auxiliar seu desenvolvimento como aprendizes autônomos. Seus professores - no caso do TTDii - ou mediadores - no caso da modalidade semi-integrada - leem os diários e propõem questionamentos e tópicos de discussão para serem exploradas nas aulas de língua (TTDii). Cavalari e Aranha (2019, p. 562) argumentam que "uma combinação de diálogos individuais por meio de diários e discussão em sala pode enriquecer tanto as aulas de inglês como língua

4 Disponível em: https://teletandemriopreto.wixsite.com/ibilce/informacoes-aos-participantes. Acesso em: 5 ago. 2019. 


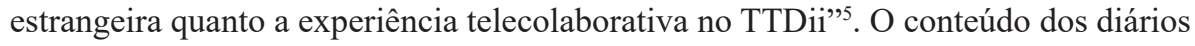
deve ainda alimentar as sessões de mediação orais, uma reunião na qual estudantes e mediadores refletem a respeito dos problemas vivenciados na prática e discutem as estratégias de aprendizagem que podem ser usadas. Outra tarefa relacionada às sessões de mediação são os procedimentos e autoavaliação realizados por meio do preenchimento de questionários, normalmente um inicial e um final. No questionário inicial, os aprendizes respondem sobre suas expectativas quanto à prática de teletandem, autoavaliam seu nível linguístico na língua alvo e estabelecem seus objetivos de aprendizagem. No questionário final, eles escrevem sobre a experiência como um todo, avaliando o cumprimento de seus propósitos. Eles também avaliam novamente seu nível linguístico. Atualmente, esses questionários são disponibilizados aos participantes por um link que redireciona a um arquivo do Google Forms.

Essa é a atual organização da prática de teletandem na UNESP-São José do Rio Preto e as tarefas apresentadas são aquelas que podem ocorrem em uma parceria de teletandem a depender as características do cenário pedagógico. Argumentamos que essas macro-tarefas, que incorporam as tarefas, dão origem a gêneros que podem ser estudados no contexto de teletandem. Como Miller (1984, p. 151) declara, "uma definição retoricamente válida de gênero precisa estar centrada não na substância ou na forma de discurso, mas na ação usada para sua realização"6. Essa ação "deve envolver situação e motivo". No caso do teletandem, as tarefas são realizadas por ações de linguagem em uma situação de aprendizagem específica cujo objetivo é aprender e trocar língua e cultura.

\section{A comunidade teletandem: uma revisão do conceito}

Defendemos que os critérios que definem a comunidade teletandem precisam ser revisados a fim de que o conceito seja ainda válido para descrever o agrupamento de pessoas envolvidas no contexto de teletandem que agora também compreende um sistema de gêneros inter-relacionados (BAZERMAN, 2006a). Tais gêneros podem ocorrer em diversos cenários pedagógicos (como descrito acima), tanto nas modalidades integrada quanto semi-integrada. Rampazzo (2017) considera que o conceito deveria incorporar também os gêneros utilizados e os outros indivíduos engajados na prática professores, mediadores, estudantes de pós-graduação.

Apresentamos agora a expansão de alguns dos itens propostos por Silva em 2012, o ajuste de outros e a inclusão de dois outros critérios para caracterizar a comunidade teletandem.

\footnotetext{
No original: "a combination of one-to-one dialog through diaries and class discussion may enrich both EFL lessons and the telecollaborative experience in iiTTD".

6 Tradução de Judith Chambliss Hoffnagel publicada em DIONÍSIO, A. P.; HOFFNAGEL, J. C. (org.). Gênero textual, agência e tecnologia. São Paulo: Parábola Editorial, 2012. p. 21-41.
} 
Segundo Silva, o primeiro critério estava relacionado às razões pelas quais os membros se uniriam na comunidade teletandem: "Uma comunidade de teletandem se estabelece a partir de afinidades de interesses, objetivos em comum, compartilhamento de um mesmo conhecimento e de prática" (SILVA, 2012, p. 72). Seus critérios, porém, não incluíam os gêneros ou a multiplicidade de propósitos que podem existir entre os membros da CT. Como apresentado na seção de fundamentação teórica, os estudantes parecem compartilhar objetivos comuns, como os resultados de Silva demonstram. De fato, Aranha e Bragagnollo (2015) também destacam que os estudantes compartilham de um objetivo similar - o propósito pedagógico de aprendizagem de uma língua - o que se torna evidente por meios das discussões de língua que ocorrem durante as sessões orais (FRANCO, 2016; FRESCHI, 2017; RAMPAZZO, 2017).

A descrição de Silva desse critério revela que ela considera apenas os alunos como membros da comunidade teletandem, desconsiderando que os professores e pesquisadores também estão envolvidos na prática de teletandem e que esses membros certamente têm objetivos diferentes daqueles dos estudantes. Enquanto os alunos querem desenvolver suas competências linguísticas e culturais, os pesquisadores podem estar interessados na coleta de dados ou analiso do ambiente de sala de aula, ou outros. $\mathrm{O}$ objetivo da coleta de dados pode não interessar aos alunos, apesar de eles darem seu consentimento para que pesquisadores utilizem os dados gerados no teletandem. Ainda em relação à multiplicidade de propósitos, se, por um lado, professores e pesquisadores podem valorizar a realização de certas tarefas, por outro, os participantes da modalidade semi-integrada, que não são avaliados por seu envolvimento, podem até ignorá-los por entender que não são relevantes para sua própria aprendizagem.

Conforme a abordagem sociorretórica de gêneros, a existência de objetivos comuns em uma comunidade leva ao uso e desenvolvimento de gêneros, os quais são compartilhados entre os membros (SWALES, 1990, 1998, 2016). Silva (2012) não inclui este aspecto em sua definição porque, quando apresenta seu estudo, investigações sobre a existência de gêneros na comunidade teletandem ainda não haviam sido conduzidos. Atualmente, Aranha (2014), Rampazzo e Aranha (2018) e Rampazzo e Aranha (2019), por exemplo, sugerem que a sessão oral de teletandem é um gênero. Rampazzo e Aranha (2018) investigaram os primeiros 15 minutos da sessão oral de teletandem inicial (SOTi) e identificaram nela um padrão retórico. A esse respeito, Aranha (2014) ainda sugere que as diferentes atividades que ocorrem no teletandem podem formar um sistema de gêneros inter-relacionados. De acordo com Bazerman (2006b, p. 23), "gêneros são os lugares familiares para onde nos dirigimos para criar ações comunicativas inteligíveis uns com os outros e são os modelos que utilizamos para explorar o não-familiar", e as diversas atividades no teletandem provavelmente são esses lugares.

Identificamos a necessidade de expandir esse critério de modo que ele inclua a multiplicidade de propósitos entre os membros da comunidade teletandem e a criação e uso de gêneros para servir aos seus propósitos comunicativos. O primeiro critério passa então a ser "A comunidade teletandem se forma por conta de interesses similares, objetivos comuns e porque seus membros compartilham de conhecimento e prática 
comuns. Eles desenvolvem gêneros para cumprir seus propósitos, os quais podem ou não ser os mesmos para cada membro".

O segundo critério no trabalho de Silva (2012, p. 72) é "as interações entre seus membros são realizadas com frequência, tendo como base um processo de cooperação ou de troca (reciprocidade) (feedback) e a construção do conhecimento, provocando um sentimento de pertencimento". Este critério não foi revisado porque as interações ${ }^{7}$ entre os membros ainda ocorrem regularmente. Durante o período estabelecido para uma parceria, os estudantes falam com seus parceiros semanalmente tanto durante as SOTs quanto por meio do e-mail; professores estão em contato com seus alunos, comentando nos seus diários, encontrando-se com eles para as sessões de mediação e, na modalidade integrada, para aulas de línguas; e os professores em cada instituição frequentemente conversam entre si para assegurar que que os procedimentos estão tendo os resultados esperados e, ocasionalmente, fazer ajustes.

Esse aspecto de interação frequente corresponde à definição de Swales (1998) de comunidade discursiva de lugar, uma vez que ele declara que os membros dessas comunidades trabalham juntos regularmente como parece ser o caso do teletandem. Além disso, os membros de fato oferecem feedback aos seus pares: os estudantes aos parceiros durante as sessões orais; os professores aos estudantes; os professores entre si quando discutem as parcerias; e os pesquisadores quando estudam os trabalhos uns dos outros ou quando compartilham seus trabalhos nos eventos acadêmicos.

O terceiro critério de Silva $(2012$, p. 72$)$ é provavelmente o mais alterado. Esse critério estabelece que "os membros de uma comunidade de teletandem são 'não-presentes', desterritorizados”. Em relação aos papéis de outros indivíduos na comunidade, além dos estudantes Luvizari-Murad (2016) destaca como o teletandem funciona com base na Teoria da Atividade (ENGESTRÖM, 1987) e nos envolvidos em uma parceria. Ela argumenta que a modalidade institucional integrada corresponde a uma variedade de sistemas de atividades inter-relacionados e organizados em um macro e um micro-contexto. O macro-contexto, segundo a autora, é composto por um sistema de atividade formado por uma comunidade de pesquisadores que incluem os professores-coordenadores, alunos de pós-graduação, orientações para a prática de teletandem e ferramentas. O micro-contexto, por outro lado, equivale ao sistema de atividade de cada par de estudantes e as tarefas que eles realizam. Ela menciona que, no teletandem institucional integrado, há

[...] múltiplas vozes, uma vez que possui todos os diferentes sujeitos citados como suas histórias, culturas e posições na divisão do trabalho, além da cultura institucional do ambiente de realização da atividade e a cultura teórica criada por toda a comunidade de pesquisadores e praticantes de TTD que antecederam o presente momento histórico. (LUVIZARI-MURAD, 2016, p. 16).

Por interações compreendemos todos os tipos de comunicação envolvidos na prática. 
Luvizari-Murad (2016) destaca a participação engajada de estudantes, que estão em contato com seus parceiros, e a participação de professores e pesquisadores na atividade de teletandem

A esse respeito, considerando os papéis exercidos por professores e pesquisadores no teletandem, tanto na modalidade integrada quanto na semi-integrada, argumentamos que eles não podem ser excluídos da comunidade teletandem. Nesse caso, poderíamos dizer que há diferentes níveis de participação na comunidade: os estudantes, os professores responsáveis pelas aulas de línguas ou os mediadores; e os pesquisadores, os quais podem estar em níveis distintos de seus estudos acadêmicos também, desde estudantes de graduação até os de pós-doutorado.

Como os estudantes não são os únicos membros na comunidade teletandem, não podemos dizer que todos os membros da CT são "não-presentes", já que a interação não necessariamente vai ser virtual, tal como é entre os parceiros - brasileiros e estrangeiros. Interações entre os membros ocorrem das seguintes maneiras: estudante - estudante (virtual); estudantes - professores/mediadores (virtual ou face-a-face); professor professor (normalmente virtual); pesquisador(es) - pesquisador(es) (virtual ou face-aface); pesquisadores - estudantes - professores (virtual ou face-a-face). Os membros da comunidade teletandem, então, navegam por meio de ambientes multimodais, os quais podem ou não ser virtuais. Entretanto, é importante destacar que independentemente de como a interação ocorre, os membros trabalham juntos regularmente, o que corrobora a definição de comunidade discursiva de lugar (SWALES, 1998) e comunidade discursiva local (SWALES, 2016). O terceiro critério para definir a CT agora inclui "A comunidade teletandem têm membros de diferentes status: estudantes, professores, mediadores e pesquisadores. Alguns desses membros podem ser 'não-presentes'."

O quarto item na definição de Silva $(2012$, p. 72) permanece o mesmo: "uma comunidade de teletandem cultiva formas próprias de comunicação virtuais". Este não foi modificado porque os membros da comunidade teletandem usam recursos de comunicação online para realizar seus trabalhos, tais como Skype, Zoom ${ }^{8}$, Google Docs, Google Drive, e-mails 9 . Outros recursos também são utilizados, como documentos PowerPoint e vídeos para a apresentação do tutorial. Isso também confirma o segundo critério da comunidade discursiva proposto por Swales (2016), de que uma CD tem mecanismos de intercomunicação e atualmente fazem uso de tecnologias digitais para promoverem contato.

O quinto critério de Silva (2012, p. 72) destacou que há uma "netiqueta" entre os membros da comunidade teletandem. Ela menciona que "as comunidades de teletandem desenvolvem um conjunto de regras, coletivamente, que regem suas interações ('netiqueta')". Esse critério foi expandido para incluir o conjunto de regras que regulam as interações face-a-face e também as relações silenciais que podem existir entre os membros da CT.

\footnotetext{
8 Disponível em: http://zoom.us. Acesso em: 5 ago. 2019.

9 Veja Cavalari (2018) para mais informações sobre o uso de ferramentas tecnológicas no teletandem.
} 
Os parceiros desenvolvem um conjunto de regras que rege a comunicação virtual entre eles e, além disso, também precisam estabelecer os acordos em relação ao uso de línguas em cada metade da SOT, a forma de correção e o gerenciamento dos encontros para cumprirem os princípios do teletandem. Além de observarem os princípios, os estudantes devem estar atentos ao cronograma e aos prazos estabelecidos por seus professores, preencherem os questionários e participarem do tutorial e das sessões de mediação. Professores, mediadores e estudantes também estabelecem um conjunto de regras que regulam suas interações: (i) via e-mail (enviar e responder à informação), (ii) via Google Drive (permitir acesso a arquivos, comentar nos diários), (iii) face-aface, nas sessões de mediação e aulas. Professores e mediadores precisam assegurar que fornecem todas as informações a tempo e os estudantes precisam responder a elas.

Além disso, acreditamos que os membros na CT estabelecem relações silenciosas, tácitas, segundo a definição de Swales (2016) que sugere que há um entendimento de que há coisas que não precisam ser ditas ou explicadas em detalhe. Os membros da CT parecem saber aquilo é que apropriado ou inapropriado dizer entre parceiros e professores. Sobre isso, Souza (2016) ressalta que os estudantes tendem a evitar corrigir seus parceiros com frequência porque tentam criar uma atmosfera amigável como uma forma de preservar a face. Rampazzo (2017) também aponta que os estudantes tendem a ser simpáticos e educados com seus parceiros em seu primeiro encontro como uma forma de assegurar uma boa relação. Professores, por sua vez, também precisam estar atentos ao que pode ser dito aos seus pares quanto à parceira e a como irão lidar com questões do dia-a-dia. Procedimentos de abordagem não são ditos ou ensinados aos membros, por isso, podemos argumentar que existem relações silenciosas na comunidade teletandem, já que parece haver um entendimento de que há coisas que não precisam ser ditas ou enfatizadas neste contexto telecolaborativo de aprendizagem. O quinto critério é então expandido para "A comunidade teletandem desenvolve coletivamente um conjunto de regras que rege suas interações, seja online ("netiqueta") ou entre os membros que se encontram face-a-face. A comunidade teletandem também estabelece relações silenciosas, tácitas, daquilo que é (in) apropriado para dizer aos parceiros".

O último item para descrever a comunidade teletandem, "os membros de uma comunidade de teletandem compartilham um léxico específico e uma comunicação bilíngue" (SILVA, 2012, p. 72), também foi revisto para incluir o que é entendido por "léxico especializado". Em sua análise, Silva (2012) considera que o uso de emoticon nos chats durante as sessões orais é léxico especializado. Swales (2016) defende que a terminologia especializada usada por comunidades discursiva pretende tornar a comunicação mais efetiva e restringi-la aos membros. Quanto aos emoticons, ferramentas de comunicação típicas de ambientes virtuais ${ }^{10}$, pode ser compreendida como léxico especializado em qualquer comunicação virtual escrita, mas não apenas

10 Devido ao desenvolvimento tecnológico, o chat não é mais utilizado como ferramenta principal de comunicação síncrona. 
eles, uma vez que existem outros termos na CT que poderiam ser considerados terminologia especializada.

Rampazzo (2017) argumenta que os nomes dados aos gêneros - sessão oral de teletandem, por exemplo - usados na comunidade teletandem poderiam também ser vistos como terminologia especializada porque são específicos desse contexto. De fato, mesmo o nome do projeto, teletandem, pode não representar muito àqueles que não parte da comunidade. Adicionalmente, os termos tutorial, diário de aprendizagem e sessão de mediação, por exemplo, podem assumir outro sentido em contextos distintos. Além disso, há também o uso de abreviações na comunidade teletandem, tais como TTD, para teletandem, TTDii, para teletandem institucional integrado, SOT, para sessão oral de teletandem, entre outros.

Quanto à comunicação, ela é bilíngue para atender um dos princípios do teletandem, o de separação de línguas. A comunicação é bilíngue entre os estudantes, que podem alternar o uso de língua durante as sessões orais, e pode ser bilíngue entre estudantes e professores também. O sexto critério é então adaptado para "Os membros da comunidade teletandem compartilham de léxico especializado e comunicação bilíngue. A terminologia especializada inclui não apenas a que é típica da comunicação virtual, mas também a nomenclatura dada aos gêneros e modalidades e o nome do projeto".

Silva estabelece apenas seis critérios para descrever a comunidade teletandem. No entanto, defendemos a inclusão de dois outros para que se tenha uma caracterização mais completa da CT. O sétimo critério compreende a posição assumida pelos participantes. Propomos, então, incluir que "Há uma hierarquia entre os membros da comunidade teletandem, os quais estão cientes de sua história e tentam comunicar suas tradições para novos membros por meio de tutoriais e sessões de mediação." Esse critério se baseia em Swales (2016), que argumenta que há uma hierarquia implícita ou explícita entre os membros de uma comunidade discursiva. Acreditamos que há uma relação de hierarquia na comunidade teletandem. Como indicado anteriormente, há três níveis de participação na CT: os estudantes, os professores e os pesquisadores. Em cada nível, há diferentes níveis de expertise, seja por conta do tempo de prática - há estudantes participando do teletandem pela primeira vez e outros que já participaram anteriormente -, ou por conta do tempo de observação e estudo do contexto - um novo pesquisador no teletandem provavelmente não terá o mesmo nível de expertise daquele que conduz estudos no contexto há anos. Sobre isso, poderíamos dizer que quanto mais estudos e práticas no contexto, maior é o nível de expertise de um membro.

Associado a essa hierarquia, os membros de um nível mais alto de expertise na CT preocupam-se em compartilhar sua história e prática a novos membros. Enquanto os estudantes podem não estar cientes da história do projeto em detalhes, eles têm a oportunidade de aprender um pouco nos tutoriais, quando o ambiente é apresentado, e nas sessões de mediação, quando têm a oportunidade de discutir sobre questões de aprendizagem e trocarem experiência. Os pesquisadores, por sua vez, têm mais consciência da história e desenvolvimento do projeto, assim como os professores - 
pelo menos no Brasil - que estão envolvidos na prática há mais tempo e preparam os materiais para os tutoriais.

Por fim, o oitavo e último critério adicionado destaca que "na comunidade teletandem, há troca contínua de seus membros". Isso pode ocorrer a cada semestre para os estudantes e a cada processo seletivo dos cursos de pós-graduação no caso dos pesquisadores. A cada semestre, os professores organizam parcerias com base no calendário acadêmico das instituições do Brasil e no exterior. O número total de sessões que ocorre cada vez varia, mas, geralmente, são realizadas entre 5 e 8 sessões para cada grupo por semestre. Durante esse período, há a participação de estudantes matriculados nas aulas de línguas - no caso da modalidade integrada - e de estudantes voluntários de diversos cursos de graduação - no caso da modalidade semi-integrada. Apesar de alguns desses estudantes poderem ter participado do teletandem anteriormente, indiferentemente da modalidade, normalmente, muitos estão participando pela primeira vez. Como resultado, há substituição parcial de membros da CT a cada semestre, o que também torna necessário a organização de tutoriais todo semestre. As chances de permanência na comunidade são maiores para os professores e pesquisadores no teletandem, uma vez que eles tendem a continuar envolvidos na prática por mais tempo. No entanto, pode haver flutuação no grupo dos pesquisadores conforme novos estudantes de pós-graduação juntam-se à equipe de pesquisadores e outros defendem suas dissertações e teses.

Finalmente, nesta seção, apresentamos os oito critérios organizados em uma lista:

1. A comunidade teletandem se forma por conta de interesses similares, objetivos comuns e porque seus membros compartilham de conhecimento e prática comuns. Eles desenvolvem gêneros para cumprir seus propósitos, os quais podem ou não ser os mesmos para cada membro.

2. As interações entre seus membros são realizadas com frequência, tendo como base um processo de cooperação ou de troca (reciprocidade) (feedback) e a construção do conhecimento, provocando um sentimento de pertencimento.

3. A comunidade teletandem têm membros de diferentes status: estudantes, professores, mediadores e pesquisadores. Alguns desses membros podem ser "não-presentes".

4. A comunidade teletandem tem seus próprios mecanismos de comunicação virtual.

5. A comunidade teletandem desenvolve coletivamente um conjunto de regras que rege suas interações, seja online ("netiqueta") ou entre os membros que se encontram face-a-face. A comunidade teletandem também estabelece relações silenciosas, tácitas, daquilo que é (in)apropriado para dizer aos parceiros.

6. Os membros da comunidade teletandem compartilham de léxico especializado e comunicação bilíngue. A terminologia especializada inclui não apenas a que é típica da comunicação virtual, mas também a nomenclatura dada aos gêneros e modalidades e o nome do projeto. 
7. Há uma hierarquia entre os membros da comunidade teletandem, os quais estão cientes de sua história e tentam comunicar suas tradições para novos membros por meio de tutoriais e sessões de mediação.

8. Na comunidade teletandem, há troca contínua de seus membros.

\section{Considerações finais}

Este trabalho teve como objetivo apresentar uma discussão sobre o conceito de comunidade discursiva em um contexto multimodal, multicultural e telecolaborativo chamado teletandem. Silva (2012) havia apresentado anteriormente uma definição de comunidade teletandem (CT) com base na associação de três conceitos: comunidade discursiva (SWALES, 1990), comunidade de prática (WENGER, 1998) e comunidade virtual (LÈVY, 1999). Considerando que as práticas telecolaborativas evoluem e mudam com o tempo, parecia haver a necessidade de rever os critérios a fim de que continuassem a ser válidos para descrever o agrupamento de pessoas envolvidas no teletandem.

Além de observar as características da CT que são típicas de comunidades online e comunidade de prática, a definição de comunidade discursiva discutida por Swales (2016) é eficaz para discutir o conceito de comunidade teletandem; entretanto, a redefinição de critérios sugerida aqui é ainda uma combinação dos três conceitos como apresentado em Silva (2012) devido à natureza prática e virtual da telecolaboração.

Nossa investigação das características da comunidade teletandem indica que as pessoas envolvidas na prática - seja como professor, pesquisador ou estudante - são membros de uma comunidade discursiva "folocal", nos termos de Swales (2016). Isso porque os membros precisam observar tanto os aspectos que regem as relações locais membros que se encontram pessoalmente no contexto do laboratório local - e os que controlam a comunicação virtual - membros que se encontram virtualmente ou trocam informações de modo virtual. Os membros da CT precisam estar cientes dos gêneros que ocorrem nos arranjos locais ou virtuais. Em outras palavras, eles precisam adequar seu comportamento, discurso e comunicação conforme aquilo que é esperado deles em situações sociais recorrentes e dos propósitos que objetivam atingir. As relações entre membros também diferem porque são organizadas por participantes distintos com papéis específicos.

Além disso, a própria natureza do projeto teletandem aponta para a organização de uma comunidade folocal, uma vez que a telecolaboração é situada em um mundo globalizado com o objeto de preparar aprendizes para operar em contatos multilíngues e multiculturais, como defendido por Helm e Guth (2010). As forças externas, portanto, têm tanta influência quanto as locais.

Ademais, além de compartilhar um conjunto de regras e serem localizados tanto regional quanto virtual e globalmente, os membros da comunidade teletandem (e, provavelmente, outros projetos telecolaborativos) desenvolvem terminologias especializadas. Eles também formam um grupo complexo e multifacetado de indivíduos 
uma vez que existem membros de diferentes níveis (professores, pesquisadores e estudantes), há uma hierarquia entre um nível e outro e entre níveis (membros mais ou menos experientes) e substituição parcial de membros.

As práticas telecolaborativas estão frequentemente sendo ajustadas, não apenas porque são sustentadas por ferramentas de tecnologias digitais em constante mudança, mas também porque podem assumir dinâmicas organizacionais específicas. Por essa razão, acreditamos que as comunidades que ocasionalmente se formam nesses projetos precisam ser continuamente estudadas.

\section{Agradecimento}

À Fundação de Amparo à Pesquisa do Estado de São Paulo (FAPESP).

RAMPAZZO, L.; ARANHA, S. Revisiting the concept of community to foster its applicability to telecollaboration. Alfa, São Paulo, v. 63, n.2, p.373-396, 2019.

- ABSTRACT: The aim of this article is to discuss the concept of community in multimodal contexts of telecollaborative projects, specifically the one named teletandem. Discourse communities (DC) are groupings of individuals who get together in order to achieve their communicative purposes through genres (SWALES, 1990). Although the concept has been extensively discussed in academic settings, there seems to be a lack of studies involving the theme and its importance for telecollaboration. One attempt in doing so is Silva's (2012) account of the teletandem community, in which she investigates students who participate in the project Teletandem Brasil Foreign Languages for All (Teletandem Brasil: Lingua Estrangeira para Todos). Our starting point is her criteria for defining such a community and our analysis derives from our intense observation of teletandem practice. The results indicate that members of communities that are occasionally gathered in telecollaboration contexts tend to be governed by local and external rules, form complex organizations and share genres to achieve their goals.

- KEYWORDS: Telecollaboration. Discourse Community. Teletandem Community. Genres.

\section{REFERÊNCIAS}

ARANHA, S. Os gêneros na modalidade de teletandem institucional integrado: a primeira sessão de interação. In: NASCIMENTO, E. L.; ROJO, R. H. R. (org.). Gêneros de texto/discurso e os desafios da contemporaneidade. Campinas: Pontes, 2014. p. 97-117.

ARANHA, S. A argumentação nas introduções de trabalhos da área de Química. 1996. 104 f. Dissertação (Mestrado em Linguística Aplicada ao Ensino de Línguas) LAEL, Pontifícia Universidade Católica de São Paulo, São Paulo, 1996. 
ARANHA, S.; BRAGAGNOLLO, R. M. Genres and Teletandem: Towards a successful relationship. In: LIMA LOPES, R. E.; FISCHER, C. M.; GAZOTTI-VALIM, M. A. Perspectivas em línguas para fins específicos: Festchrift para Rosinda Ramos. Campinas: Pontes, 2015. p. 81-91.

ARANHA, S.; CAVALARI, S. M. S. A trajetória do projeto Teletandem Brasil: da modalidade Institucional Não-Integrada à Institucional Integrada. The ESPecialist, São Paulo, v. 35, n.2, p. 183-201, 2014.

ARANHA, S.; LEONE, P. The development of DOTI (Databank of oral teletandem interaction). In: FISHER, D.; BEIBWENGER, M. Investigating computer-mediated communication corpus-based approaches to language in the digital world. Ljubljana: Ljubljana University Press, 2017. p. 172-190.

ARANHA, S.; LEONE, P. DOTI: Databank of Oral Teletandem Interactions. In: JAGER, S.; KUREK, M. (ed.). New directions in telecollaborative research and practice: selected papers from the second conference on telecollaboration in higher education. Dublin: Research-publishing.net, 2016. p. 1-6.

ARANHA, S.; LOPES, Q. B. Moving from an internal databank to a sharable multimodal corpus: the MulTeC case. The ESPecialist, São Paulo, v. 40, n. 1, 2019.

ARANHA, S.; LUVIZARI-MURAD, L.; MORENO, A. C. A criação de um banco de dados para pesquisas sobre aprendizagem via teletandem institucional integrado (TTDii). Revista (Con)textos Linguísticos, Vitória, v. 9, p. 274-293, 2015.

ARANHA, S.; TELLES, J. Os gêneros e o projeto Teletandem Brasil: relação entre compartilhamento e sucesso interacional. In: SIGET: SIMPÓSIO INTERNACIONAL DE ESTUdOS DE GÊNEROS TEXTUAIS, 6., 2011, Natal. Anais [...], Natal, 2011. Disponível em: https:/www.ibilce.unesp.br/Home/Departamentos/LetrasModernas/ teletandem/os-generos-e-o-projeto-teletandem-brasil-relacao-entre-compartilhamentoe-sucesso-interacional-2.pdf. Acesso em: 6 set 2019.

BAZERMAN, C. Gêneros textuais, tipificação e interação. Trad.: Judith Chambliss Hoffnagel. 3. ed. São Paulo: Cortez, 2006a.

BAZERMAN, C. Gênero, agência e escrita. São Paulo: Cortez, 2006b.

BRAMMERTS, H. Tandem language learning via the internet and the International E-Mail Tandem Network. In: LITTLE, D.; BRAMMERTS, H. (ed.). A Guide to Language Learning in Tandem via the Internet. Dublin: Trinity College, 1996. p. 9-21. (CLCS Occasional Paper, 46).

CAVALARI, S. M. S. Integrating telecollaborative language learning into Higher Education: a study on teletandem practice. BELT: Brazilian English Language Teaching Journal, Porto Alegre, v. 9, n. 2, p. 417-432, 2018. 
CAVALARI, S. M. S.; ARANHA, S. The Teacher's Role in Telecollaborative Language Learning: The Case of Institutional Integrated Teletadnem. Revista Brasileira de Linguística Aplicada, Belo Horizonte, v. 19, n. 3, p. 555-578, 2019.

CAVALARI, S. M. S.; ARANHA, S. Teletandem: integrating e-learning into the foreign language classroom. Acta Scientiarium: Language and Culture, Maringá, v. 38, n. 4, p. 327-336, Oct.-Dec. 2016.

DARHOWER, M. A Tale of Two Communities: Group Dynamics and Community Building in a Spanish-English Telecollaboration. CALICO Journal, Sheffield, v.24, n.3, p. 561-589, 2007.

DÖRNYEI, Z. Research Methods in Applied Linguistics: Quantitative, Qualitative and Mixed Methodologies. Oxford: Oxford University Press, 2007.

ENGESTRÖM, Y. Learning by expanding: An activity-theoretical approach to developmental research. Helsinki: Orienta-Konsultit, 1987.

FOUCHER, A. Didactique des Langues-Cultures et Tice: scénarios, tâches, interactions. 2010. Disponível em: https://tel.archives-ouvertes.fr/tel-00812813/ document. Acesso em: 5 set. 2019.

FRANCO, G. R. Aspectos linguísticos emergentes em sessões de Teletandem: uma análise a partir da conscientização da linguagem. 2016. 172f. Dissertação (Mestrado em Estudos Linguísticos) - Instituto de Biociências, Letras e Ciências Exatas, Universidade Estadual Paulista, São José do Rio Preto, 2016.

FRESCHI, A. C. A avaliação por pares no teletandem institucional integrado: um estudo de caso sobre o feedback linguístico nas sessões orais em português. 2017. 120f. Dissertação (Mestrado em Estudos Linguísticos) - Instituto de Biociências, Letras e Ciências Exatas, Universidade Estadual Paulista, São José do Rio Preto, 2017.

FUNO, L. B. A. Teletandem: um estudo sobre identidades culturais e sessões de mediação da aprendizagem. 2015. 190f. Tese (Doutorado em Estudos Linguísticos) Instituto de Biociências, Letras e Ciências Exatas, Universidade Estadual Paulista, São José do Rio Preto, 2015.

HELM, F.; GUTH, S. The multifarious goals of telecollaboration 2.0: theoretical and practical implications. In: HELM, F.; GUTH, S. (ed.). Telecollaboration 2.0: Language Literacies and Intercultural Learning in the $21^{\text {st }}$ century. New York: Peter Lang, 2010. p. 69-106.

HEMAIS, B.; BIASI-RODRIGUES, B. A proposta de John Swales para o estudo de gêneros textuais. In: MEURER, J. L.; BONINI, A.; MOTTA-ROTH, D. Gêneros: teorias, métodos, debates. São Paulo: Parábola Editorial, 2005. p. 108-129.

LAVE, J.; WENGER, E. Situated learning: Legitimate peripheral participation. New York: Cambridge University Press, 1991. 
LÈVY, P. Cyberculture. Trad. de Carlos Iriney da Costa. São Paulo: Ed. 34, 1999.

LUVIZARI-MURAD, L. Ciclos de aprendizagem expansiva no processo de reorganização da coleta de dados em TTDii. 2016. Relatório final de pesquisa (PósDoutorado em Estudos Linguísticos) - Instituto de Biociências, Letras e Ciências Exatas, Universidade Estadual Paulista, São José do Rio Preto, 2016.

MANGENOT, F.; SOUBRIÉ, T. Créer une banque de tâches Internet: quels descripteurs pour quelles utilisations? In: FOUCHER, A.-L.; POTHIER, M.; RODRIGUES, C.; QUANQUIN, V. (dir.). La tâche comme point focal de l'apprentissage. ClermontFerrand, 2010. Disponível em: https://edutice.archives-ouvertes.fr/file/index/ docid/495054/filename/Mangenot.pdf. Acesso em: 5 set. 2019.

MASON, J. Qualitative Researching. London: Sage Publications, 2002.

MILLER, C. R. Genre as social action. Quartely Journal of Speech, Philadelphia, v.70, p. 151-167, 1984.

MOITA-LOPES, L. P. Pesquisa interpretativista em linguística aplicada: a linguagem como condição e solução. DELTA: Documentação e Estudos em Linguística Teórica e Aplicada, São Paulo, v. 10, n. 2, p. 329-338, 1994.

O’DOWD, R. (ed.). Online Intercultural Exchange: Policy, Pedagogy, Practice. New York; London: Routledge, 2013.

RAMPAZZO, L. Gêneros textuais e telecolaboração: uma investigação da sessão oral teletandem inicial. 2017. 134 f. Dissertação (Mestrado em Estudos Linguísticos) Instituto de Biociências, Letras e Ciências Exatas, Universidade Estadual Paulista, São José do Rio Preto, 2017.

RAMPAZZO, L.; ARANHA, S. Telecollaboration and genres: a new perspective to understand language learning. Journal of Virtual Exchange, Dublin, v.2, 1-22, 2019.

RAMPAZZO, L.; ARANHA, S. A sessão oral de teletandem inicial: a estrutura retórica do gênero. DELTA: Documentação e Estudos em Linguística Teórica e Aplicada, São Paulo, v. 34, n.1, p. 449-473, 2018.

SILVA, J. M. Projeto Teletandem Brasil: As relações entre as comunidades virtuais, as comunidades discursivas e as comunidades de prática. 2012. 152f. Dissertação (Mestrado em Estudos Linguísticos) - Instituto de Biociências, Letras e Ciências Exatas, Universidade Estadual Paulista, São José do Rio Preto, 2012.

SOUZA, M. G. Teletandem e mal-entendidos na comunicação intercultural online em língua estrangeira. 2016. 170f. Tese (Doutorado em Estudos Linguísticos) Instituto de Biociências, Letras e Ciências Exatas, Universidade Estadual Paulista, São José do Rio Preto, 2016. 
SWALES, J. M. Reflections on the concept of discourse community. Asp, Bordeaux, v.69, p. 7-19, 2016.

SWALES, J. M. Research Genres. Cambridge: Cambridge University Press, 2004.

SWALES, J. M. Other floors, other voices: a textography of a small university building. Mahwah: Lawrence Erlbaum Associates, 1998.

SWALES, J. M. Genre and Engagement. Revue Belge de Philologie et d'Histoire, Brussels, n.3, p. 687-698, 1993.

SWALES, J. M. Genre Analysis: English in academic and research settings. Cambridge: Cambridge University Press, 1990.

TELleS, J. A. Projeto Teletandem Brasil: Línguas Estrangeiras para Todos: Ensinando e Aprendendo línguas estrangeiras in-tandem via MSN Messenger. Assis: Faculdade de Ciências e Letras, UNESP, 2006. Projeto enviado à Fapesp. Não publicado.

VASSALLO, M. L.; TELLES, J. A. Foreign Language learning in-tandem: Theoretical principles and research perspectives. The ESPecialist, São Paulo, v. 25, n. 1, p. 1-37, 2006.

WENGER, E. Communities of Practice: learning, meaning and identity. Cambridge: Cambridge University Press, 1998.

ZAKIR, M. A. Cultura e(m) telecolaboração: uma análise de parcerias de teletandem institucional. 2015. 232f. Tese (Doutorado em Estudos Linguísticos) - Instituto de Biociências, Letras e Ciências Exatas, Universidade Estadual Paulista, São José do Rio Preto, 2015.

Recebido em 8 de junho de 2018

Aprovado em 25 de março de 2019 